\title{
ACHIEVING THE SUCCESSFUL LEAN IMPLEMENTATION AT MANUFACTURING COMPANIES IN VIETNAM: AWARENESS OF CRITICAL BARRIERS
}

\author{
NGUYEN THI DUC NGUYEN \\ Ho Chi Minh City University of Technology, Vietnam National University, HCMC \\ ntdnguyen@hcmut.edu.vn \\ DO TRI DANG \\ Ho Chi Minh City University of Technology, Vietnam National University, HCMC \\ dangdo1710@gmail.com
}

HUYNH THI PHUONG LAN

Ho Chi Minh City University of Technology, Vietnam National University, HCMC htplan@hcmut.edu.vn

(Received: December 18, 2016; Revised: March 8, 2017; Accepted: April 10, 2017)

\begin{abstract}
This study focuses on identifying the critical barriers/difficulties and exploring roots of barriers/difficulties for successful Lean implementation at manufacturing companies in Vietnam. The literature review and in-depth interview are applied in this study. The literature review is done to review and to obtain experiences of the inhibitors of Lean Implementation from previous studies. In-depth interview is conducted with eight experts of eight manufacturing companies deployed Lean to explore and identify the critical barriers/difficulties for Lean implementation successfully. As a result, it finds that seven key barriers inhibiting the successful Lean implementation come from the leadership; the employees; the workplace; resources; operation process; the integration with customers; and from the integration with suppliers. These challenges are not easy and take a lot of time to overcome, though, this study provides helpful advices for business in Vietnam who has plans to follow Lean implementation in looking back to the company and restructuring strategies, objectives so that Lean implementation process would be more efficient and more open.
\end{abstract}

Keywords: Lean Manufacturing; Lean Production, Lean barriers/difficulties; manufacturing companies; Vietnam.

\section{Introduction}

Production is the process which transforms inputs (raw material, semi-finished goods, labor, equipment, capital, information, management) into goods or service in order to satisfy customer expectation and then organization can get the profit. Therefore, this activity is supposed as a key process which plays an important role in value chains of any industry and should be seriously considered in organizational strategy development as well as other functions (Swamidass, Baines \& Darlow, 2001). In the globalization era with the complicated development technology, severe competition and continuously increasing of customer requirement which are focused on price, quality, speed of response force firms to improve their products and production processes as well (Alukal, 2003; Tracey, Vonderembse \& Lim, 1999). As a result, many firms apply Lean as a tool to help them achieve competitive advantages (Taleghani, 2010).

Lean Production or Lean Manufacturing is known as a culture (Lixia \& Bo, 2010; Angelis et al, 2011), or a philosophy (Bhasin $\&$ Burcher, 2006), or a revolution (Melton, 2005) -is appeared from early 1910s, then it is 
gradually developed its foundation in Japan in 1940 (after WWII) named Toyota Production System (TPS) (Albliwi, Antony and Lim, 2015). In 1990s, TPS is imported to US and Western which is known as Lean approach (Akbulut-Bailey, Motwani và Smedley, 2012), then widely implemented as a popular method for organizational improvement activities (Peters, 2010). Lean not only focuses on eliminating wastes and non-added value activities of firms on customer's perspective but also supports firms to cut costs, reduces cycle time and lead time; thus helps firms gain competitive advantages and quickly responses to market requirements (Alukal, 2003; Albliwi, Antony and Lim, 2015). Starting from automobile industry, Lean gradually broadens its affects to other industries, service sectors, and public economics (Ballard \& Tommelein, 2012); and Lean now is known as a global standard of production system in XXI century (Berggren, 1993).

In the past 10 years, organizations in developing countries such as China, India have changed from low-cost, labor intensive production systems into Lean production which achieves higher productivity, flexibility and creates more added values (Panizzolo et al, 2012). In Vietnam, the theories of manufacturing optimization and Total Quality Management have been recognized and deployed since 1995. One of the typical events is the first Vietnam Quality Conference. However, the progress has not been effective enough to meet the requirements of the industrialization and the modernization which have been developing rapidly while the productivity in Vietnam is still at a low level in comparison with other countries (Directorate for Standards, Metrology and Quality, 2015). Particularly, in garment and textile industry, the productivity is one third if compared with the developing countries, $90 \%$ if compared with China, $75 \%$ if compared with Thailand and just higher $15 \%$ if compared with Cambodia (IMQ Corporation, 2014). In front of this situation, the Vietnamese government officially approved the national program "Improving productivity and quality of Vietnamese products by 2010" (known as Program 712) conducted by Ministry of Science and Technology and supported by the provincial agencies. The 10-year road map includes 2 phases: the 2010-2015 and the 2016-2020, which objective is to bring the tools as well as the model and management system to 60,000 firms and $100 \%$ of them will apply the quality and productivity improving projects (Directorate for Standards, Metrology and Quality, 2015). Especially, Lean manufacturing has come to Vietnam since the year 2000 and become the big trend. However, the successful businesses in applying Lean have only counted on the fingers (Hirayama Vietnam, 2015). Around 75\% companies has applied this system but the success rate is not high (Hirayama Vietnam, 2015). For instance, although Vietnam's textile and garment enterprises applying Lean affirmed the superiority of Lean in promoting business value, about $15-20 \%$, but most of the leaders must also acknowledge the Lean implementation and application is not simple and encounters many barriers (Hirayama Vietnam, 2015). Besides, Lean is also applied for services sectors with the typical examples such as banking (Techcombank) and health care (Hoan My Hospital).

Moreover, as other improvement tools, Lean implementation is not always successful (Taleghani, 2010). Regarding to Ringen and Holtskog (2013), 2 of 3 continuous improvement projects would be under expectation. Pedersen and Huniche (2011) also mention that $70 \%$ Lean projects are failed. The study of Bhasin and Burcher (2006) shows that only $10 \%$ companies are successful with Lean implementation in England. Therefore, investigation into the 
reasons and barriers leading to unsuccessful Lean implementation becomes an interesting topic. There are a great number of articles and studies on this topic, using different approaches: qualitative research, quantitative research, theoretical research, applied researches, and so on, and varying from basic research to find out the barriers or testing existing element to confirm and explore other factors (for example, Womack and Jones, 1996; Albliwi et al., 2014; Albliwi, Antony and Lim, 2015).

In Vietnam, Lean is recognized for its efficiency then, the deployments are increased significantly. However, a few enterprises were successful with Lean implementation. Only $2 \%$ of firms applying Lean in Viet Nam are successful (Le, 2013). However, most of the studies focus on the application of Lean in Vietnam (to identify and eliminate the wastes) and the key factors of success (e.g., Nguyen and Bui, 2010; Nguyen, Nguyen and Le, 2015) instead of the barriers when implementing Lean. High rate of failures and lack of information of barriers may be the main obstacles for successfully applying Lean manufacturing in Vietnam, especially the Vietnamese companies who really want to improve the current situations.

Consequently, the questions of which kinds of barriers to Lean implementation and of why those kinds of barriers that make manufacturing companies in Vietnam unsuccessful are not answered adequately. This study aims to tackle these matters by reviewing the prior studies of barriers of Lean implementation and in-depth interviewing with Lean experts for identifying the critical barriers of Lean implementation at manufacturers in Vietnam, and to propose the suggestions.

\section{Literature review}

Lean can be considered from the philosophical view as related to the guiding principles or general objectives, and from operational and practical point of view as a set of activities, tools and management techniques observed directly (Shah and Ward, 2007). In literature, the concept of Lean manufacturing and Lean production are generally considered to be interchangeable and briefly said as Lean. Lean Production is a terminology predominantly used in Europe and is the word coined by MIT group while Manufacturing is a preferred term in North America (Womack, Jones and Roos, 2007; Womack, and Jones, 2010). On the philosophical view, Lean is often called "Lean Thinking" (Womack and Jones, 1996; Boyle, Scherrer -Rathje and Stuart, 2011). Two basic concepts of Lean Thinking include eliminating waste and creating value (Murman et al, 2002). Meanwhile, on the operational perspective, Lean includes the deployment of a range of tools and techniques in the workshop aiming to minimize waste in the plant and throughout the supply chain (Shah and Ward, 2003; Shah and Ward, 2007; Boyle, Scherrer-Rathje and Stuart, 2011).

By applying the Creswell (2013)'s method for literature review, it is recognized that many studies on Lean inhibitors stand on the operational and practical point of view. And there are 15 previous studies closely related to the topic of barriers for the Lean implementation. They are a fundamental for this study, which are reviewed in Table 1 as below: 


\section{Table 1}

Barriers for the Lean implementation (reviewing the literature and results of this study)

Barriers for the Lean implementation

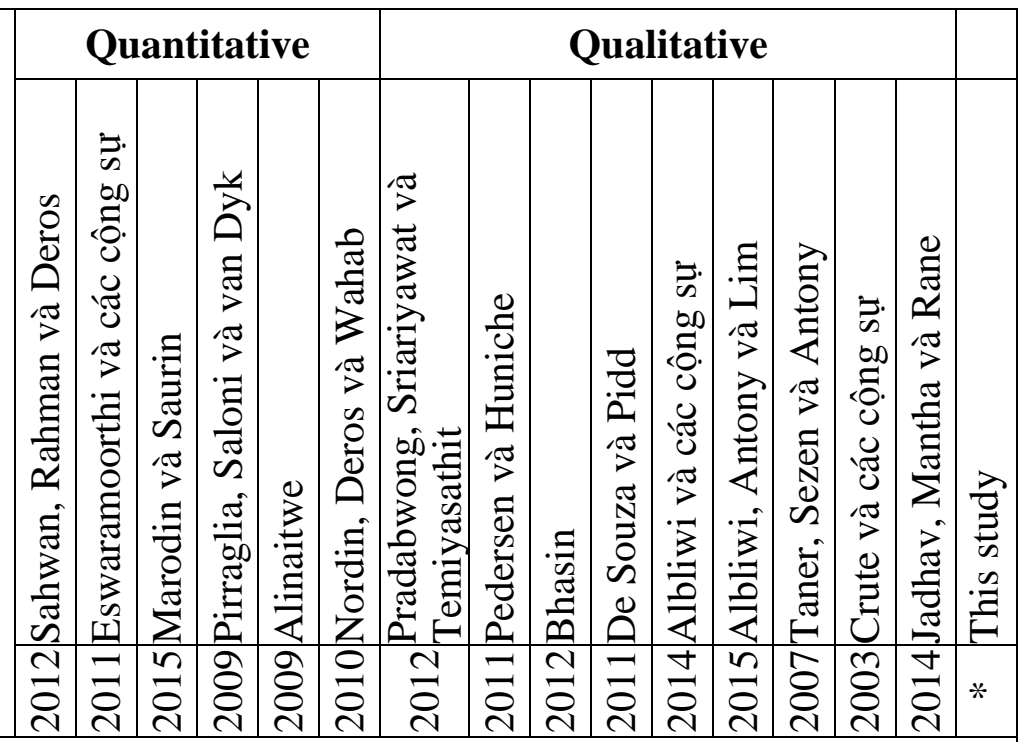

\section{Barriers from the leadership}

\begin{tabular}{|c|c|c|c|c|c|c|c|c|c|c|c|c|c|c|c|}
\hline Lack of leadership commitment & & & & $\phi$ & o & $\mathrm{x}$ & & & & $\mathrm{x}$ & & & $\mathrm{x}$ & $\mathrm{x}$ & $*$ \\
\hline $\begin{array}{l}\text { Lack of participation and support of } \\
\text { leaders }\end{array}$ & & $\phi$ & & $\phi$ & & & $\mathrm{x}$ & & & $\mathrm{x}$ & $\mathrm{X}$ & $\mathrm{x}$ & & $\mathrm{x}$ & $*$ \\
\hline $\begin{array}{l}\text { Lack of leadership awareness about the } \\
\text { effectiveness and benefits of Lean }\end{array}$ & o & $\phi$ & $\phi$ & & $\mathbf{o}$ & & & $\mathrm{X}$ & $\mathrm{x}$ & $\mathrm{x}$ & $\mathrm{X}$ & & & & $*$ \\
\hline $\begin{array}{l}\text { Lack of planning, management, } \\
\text { creating change }\end{array}$ & o & $\phi$ & $\phi$ & $\phi$ & & & $\mathrm{x}$ & $\mathrm{X}$ & & $\mathrm{x}$ & & & & $\mathrm{X}$ & $*$ \\
\hline $\begin{array}{l}\text { Negative attitude and the resistance of } \\
\text { leaders }\end{array}$ & & & $\phi$ & & $\mathbf{o}$ & & & & $\mathrm{x}$ & $\mathrm{x}$ & $\mathrm{X}$ & $\mathrm{x}$ & & $\mathrm{x}$ & $*$ \\
\hline $\begin{array}{l}\text { Project selection and use of } \\
\text { unreasonable force }\end{array}$ & & & & & & & $\mathrm{x}$ & & & $\mathrm{x}$ & $\mathrm{x}$ & & & & $*$ \\
\hline $\begin{array}{l}\text { Lack of recognition and reward to } \\
\text { encourage. }\end{array}$ & 0 & & & & & $\mathrm{X}$ & $\mathrm{x}$ & & & & & & & $\mathrm{x}$ & $*$ \\
\hline \multicolumn{16}{|l|}{ Barriers from the employees } \\
\hline $\begin{array}{l}\text { Lack of knowledge, skills and } \\
\text { implement capability }\end{array}$ & 0 & & $\phi$ & $\phi$ & & $\mathrm{X}$ & $\mathrm{x}$ & $\mathrm{x}$ & & $\mathrm{x}$ & $\mathrm{X}$ & & & & $*$ \\
\hline $\begin{array}{l}\text { Negative attitude and hindrance of } \\
\text { employees }\end{array}$ & o & & $\phi$ & & $\mathbf{o}$ & & $\mathrm{x}$ & $\mathrm{x}$ & & & $\mathrm{X}$ & $\mathrm{X}$ & & $\mathrm{x}$ & $*$ \\
\hline $\begin{array}{l}\text { Lack of patience and loss of motivation } \\
\text { after a period of Lean implementation }\end{array}$ & & $\phi$ & $\phi$ & & & & & & & & & & & $\mathrm{X}$ & $*$ \\
\hline Disunity at work within the group & & & & $\phi$ & & & & & $\mathrm{x}$ & $\mathrm{x}$ & $\mathrm{x}$ & & & $\mathrm{x}$ & $*$ \\
\hline \multicolumn{16}{|l|}{ Barriers from the workplace } \\
\hline Culture and regulations of the country & & & & & o & & & & & & $\mathrm{x}$ & & & & \\
\hline Corporate Culture & 0 & & & $\phi$ & o & $\mathrm{X}$ & $\mathrm{x}$ & $\mathrm{x}$ & $\mathrm{x}$ & $\mathrm{x}$ & & & $\mathrm{X}$ & $\mathrm{x}$ & $*$ \\
\hline
\end{tabular}




\begin{tabular}{|c|c|c|c|c|c|c|c|c|c|c|c|c|c|c|c|c|}
\hline $\begin{array}{l}\text { The missing and incomplete } \\
\text { training/coaching program }\end{array}$ & o & & & & & & $\mathrm{X}$ & $\mathrm{x}$ & & & $\mathrm{x}$ & $\mathrm{X}$ & $\mathrm{X}$ & & $\mathrm{X}$ & $*$ \\
\hline $\begin{array}{l}\text { Lack of communication and interaction } \\
\text { between all levels and different teams }\end{array}$ & & & $\phi$ & & $\phi$ & o & & $\mathrm{X}$ & & X & $\mathrm{x}$ & $\mathrm{X}$ & & & $\mathrm{x}$ & $*$ \\
\hline Restrictions on space & & $\phi$ & & & & & & & & & & & & $\mathrm{X}$ & $\mathrm{X}$ & $*$ \\
\hline $\begin{array}{l}\text { Too stable working environment to } \\
\text { form motivation }\end{array}$ & & & & $\phi$ & $\phi$ & & & $\mathrm{X}$ & & & & & & & & $*$ \\
\hline \multicolumn{17}{|l|}{ Barrier from resources } \\
\hline Lack of human resource & o & $\phi$ & $\phi$ & $\phi$ & & & & $\mathrm{x}$ & & & $\mathrm{x}$ & $\mathrm{X}$ & $\mathrm{x}$ & & $\mathrm{X}$ & \\
\hline Lack of financial resource & o & $\phi$ & $\phi$ & $\phi$ & & o & $\mathrm{X}$ & $\mathrm{x}$ & $\mathrm{X}$ & & $\mathrm{x}$ & $\mathrm{x}$ & $\mathrm{x}$ & & $\mathrm{x}$ & $*$ \\
\hline Lack of time & o & $\phi$ & & $\phi$ & & & & & $\mathrm{X}$ & & & & $\mathrm{x}$ & $\mathrm{X}$ & $\mathrm{X}$ & $*$ \\
\hline $\begin{array}{l}\text { Unqualified input equipment and } \\
\text { materials. }\end{array}$ & & $\phi$ & & & $\phi$ & o & & $\mathrm{x}$ & & & $\mathrm{x}$ & & & & $\mathrm{X}$ & $*$ \\
\hline \multicolumn{17}{|l|}{ Barriers from operation process } \\
\hline $\begin{array}{l}\text { Unable to measure benefits and the } \\
\text { level of efficiency of Lean } \\
\text { implementation or Lack of criteria, } \\
\text { measurement system or effectiveness } \\
\text { measurement activities }\end{array}$ & 0 & & & & $\phi$ & 0 & & & & $\mathrm{X}$ & $\mathrm{x}$ & & & & & $*$ \\
\hline $\begin{array}{l}\text { Strategy changes and no close link with } \\
\text { the strategy }\end{array}$ & & & & & $\phi$ & & & $\mathrm{X}$ & & $\mathrm{X}$ & $\mathrm{x}$ & $\mathrm{X}$ & & $\mathrm{X}$ & & $*$ \\
\hline $\begin{array}{l}\text { Maintain unstably and fall into old } \\
\text { paths }\end{array}$ & & & & $\phi$ & $\phi$ & & & & & & & & & & $\mathrm{X}$ & $*$ \\
\hline Failure in previous Lean projects. & o & & & $\phi$ & & & & & & & & & & & & \\
\hline \multicolumn{17}{|c|}{ Barriers from the integration with customers } \\
\hline Lack of customer focus & $\mathrm{o}$ & $\phi$ & & & $\phi$ & & & & & & $\mathrm{X}$ & & & & $\mathrm{X}$ & $*$ \\
\hline $\begin{array}{l}\text { Lack of cooperation and support from } \\
\text { customers }\end{array}$ & & $\phi$ & & & $\phi$ & & & & & & & & & & & $*$ \\
\hline $\begin{array}{l}\text { Heterogeneity in customer } \\
\text { requirements }\end{array}$ & & $\phi$ & & & & & & & & & & & & & & $*$ \\
\hline \multicolumn{17}{|c|}{ Barriers from the integration with suppliers } \\
\hline $\begin{array}{l}\text { Lack of communication and the impact } \\
\text { on suppliers }\end{array}$ & & & & & & & & & & & $\mathrm{x}$ & & & & $\mathrm{X}$ & $*$ \\
\hline $\begin{array}{l}\text { Lack of cooperation and support from } \\
\text { the vendor }\end{array}$ & & & & & $\phi$ & & & & & & & & & & $\mathrm{X}$ & $*$ \\
\hline $\begin{array}{l}\text { Unguaranteed supply chain and } \\
\text { logistics system }\end{array}$ & & $\phi$ & & & $\phi$ & & & & & & & & & & $\mathrm{X}$ & $*$ \\
\hline
\end{tabular}

Note: $\mathrm{x}$ : element was discovered in qualitative research

o: element was determined in quantitative research, confirmed by data

$\phi$ : element was determined in quantitative research, unconfirmed by data

*: element is identified by this study 


\section{Research methodology}

The methods of literature reviewing and in-depth interviewing are applied in this study. The literature review is done to review the inhibitors of Lean implementation from previous studies. In-depth interview is conducted with eight experts in industry to explore and identify the critical barriers for Lean implementation successfully. The interviewees are the managers, team leaders with at least 3-year's experience working on Lean projects (in this study, interviewees have mean 5-years'Lean working experience) at eight manufacturing companies implemeting Lean projects.

The semi-structured questionnaire is designed to interview directly with the experts. Each conversation takes at least one and half hour and the content is noted and recorded. Information and data are collected, rewritten, classified and presented carefully after each interview. Then, the data is analyzed and synthesized in the results.

\section{Research results and Discussion}

\subsection{Analyze barriers to the Lean Manufacturing implementation manufacturing enterprises at Vietnam \\ of}

On the basis of in-depth interview with eight experts in Lean implementation and the convergence the experts' opinions, the critical barriers are identified; their roots are explained in detail, and then presented as below. The critical barriers come from leadership; employees; workplace; resources; operation process; the integration with customers; and the integration with suppliers; which are presented in comparison with the literature review in Table 1.

\section{Barriers from the leadership}

The factor "Lack of leadership commitment" has been identified by experts as a significant inhibition to the Lean manufacturing implementation at each enterprise. The common explanation given for this finding is that when the leadership is lack of commitment, even staff effort or determination cannot get the consent or support from them. Leadership is the highest level with the greatest impact on every business operation activity; thus, once they did not support the deployment, there was no different way or if there is, the level of implementation is stagnant. Then, the implementer gradually loses his momentum, which leads to very low odds of success.

"Lack of participation and support of leaders" is considered as a factor hindering the implementation of Lean; however, it has lesser extent in comparison with the first factor. Commitments are in terms of awareness while participation and support are in terms of implementation; thus, two factors have to come together. When encountering difficulties, the leadership which is deficient in participation or support will get stuck there or will not be able to solve problems promptly. However, the extent of its impact just stops at hindering level, rather than a serious obstacle as considered at a different aspect, the leaders who propose guidelines and orientations while employees develop into specific work items and execute them. Therefore, asking leaders to follow all details of implementation is inconsistent.

Considering the factor "Lack of leadership awareness about the effectiveness and benefits of Lean", the fact that the leaders lack the knowledge and understanding of the concepts and principles of Lean is considered normal factor because there are many articles and current information of Lean on the internet for comfortably self-updating Lean knowledge. Besides, the experts suggest that leaders do not need to know too much expertise in Lean. The crucial thing is to have the Lean spirit, the Lean thinking and the basis of Lean in order to provide guidance and instructions for employees. Meanwhile, the fact that leaders with a lack of awareness about the benefits and efficiency of Lean to enterprises are considered as an important hindering factor. Obviously, when leaders do not have the sense of benefits from Lean for their firms, they will not have enough 
confidence and motivation to facilitate the Lean implementation. The difference in identification of these two items are entirely consistent with the fact that the higher level of leadership, the higher level of conceptual skills and human skills is; while the lower level of the professional skills (technical skills) is (Dubrin, 2011).

The factor "Lack of planning, management, creating change" received various comments from experts. However, they all have one thing in common that the two most fundamental skills for leaders among many mentioned skills are the strategic direction and vision; thus, without them will cause significant impacts. The remaining skills such as time management, change management, monitoring management are responsibilities towards the subordinate manager; therefore, leaders do not need to do these things themselves. Simultaneously, these skills mainly help manage work better and seldom affect the Lean improvement program.

"Negative attitude and the resistance of leaders" are considered a terribly hindering factor by all experts. The factor itself has been stated so clearly and its meanings have been fully revealed. The leaders are those who have strongly influential impacts in the business; thus, expressing negative attitudes and creating barriers will absolutely cause difficulties for the Lean implementation.

The factor "Project selection and use of unreasonable force" consists of two issues which are (1) selection of staff members and (2) selection of projects and allocation the priorities. With the staff selection, most experts perceive it as an obstruction. Newcomers who do not have enough knowledge can be acceptable as they will be fully trained. At the same time, if we require to hire a person with full knowledge and expertise about Lean, it is not easy owing to the high cost (especially for businesses that need a huge amount of labor force with ordinary levels and low labor costs). However, if hiring a person with no confidence, passion or improvement thinking to do jobs, it is really hard to expect for high effectiveness. Besides, the irrelevance of project selection and priority allocation is evaluated as a normal factor due to two reasons. Firstly, the management team is responsible for following up, implementing the work and most of the relevant information. Therefore, they are accountable for advising leaders to select the right projects and allocate the priority appropriately. The leader will not be the person who takes full responsibility in this situation. Secondly, if the distribution is not suitable, the activities may still keep doing without being stopped. It just becomes more slowly than expected because no matter what the project is, the goal is always making a better outcome and improving business activities.

The factor "Lack of recognition and reward to encourage" noted by most experts as an obstruction to the Lean implementation because employees are not motivated as well as appreciated their contributions, which leads to lack of fervor, enthusiasm, and voluntarism at work. At that time, they merely do the tasks grudgingly only because of the responsibility and compulsion. Then, the result will certainly not be as effective as expected or may be achieved as expected, but will not be able to exceed more than expected. However, in the long term plan, businesses need to make their employees aware that Lean operation is going into their daily work, helping them achieve greater efficiency and certainty not about building up more work, consuming more time or more efforts. Normally, employees still have to perform their work seriously, so with the Lean operation, it must also be like a habit. Until then, the encouragement or the reward will only be a support to improve the work, not an award for every person who does 'Lean'.

Above, in the group of factors "leadership", the elements which experts focus on and judge to be significant impediments to Lean manufacturing implementation of 
enterprises are "Lack of leadership commitment", "Lack of participation and support of leaders", "Lack of awareness about the effectiveness and benefits of Lean",

Negative attitude and the resistance of leaders", "Unreasonable staff selection" and " Lack of recognition and commendation to encourage".

\section{Barriers from the employees}

The factor "Lack of knowledge, skills and implement capability" is considered normal by the majority of experts; nevertheless, there is a great disparity among the remaining experts. The difference is due to their different outlook at problems and different experience in their business. For the experts, they believe that the improvement program system is given by managers or leaders of companies while workers just need to comply all available rules and guidance in earnest and that will help them achieve expected results. Therefore, the requirements of having skills or knowledge are not really necessary. What is needed is giving them the reason why to do, the methods and how to implement the methods into work. Along with that, building an improved mindset for employees so as to help them self-view the inappropriate stages in work is also essential. Besides, at the time when new employees are hired on, the fact that they do not know or have any concept about Lean is very popular. Nevertheless, enterprises can fully apply the training program or send them short-course training. Then, after a period of time to be exposed to practical work and have good instructors, they will gradually accumulate necessary knowledge and skills for their job in the company. From the perspective of the experts who evaluate this factor as a major hindrance, they argue that the employees are people who directly interact with the work so they must have understood the nature of the problem, which means that lack of knowledge or skills will prevent the work from being smooth and efficient.

The factor "Negative attitude and hindrance of employees" is also received different perspectives from experts; however, the notification that this is a barrier that needs to be focused more. In the experts' views, when the workers are aware of the Lean and the Lean implementation; but they still show a negative attitude and find ways to hinder, those people are too conservative, unwilling to accept better changes and even not afraid of breaking rules and regulations, and trying to sabotage. With these thoughts and deliberate act, how can we deploy Lean? On the other hand, from the opinion of experts whose considerations of this factor is at normal factor, those leaders are the leading thinkers under strong schools using power and influence to manage and keep everything under control. Thus, this factor to them can be controlled easily and quickly without any obstruction. At that time, if any employee refuses to adapt to changes or improvements despite of having been persuaded and keeps showing negative attitudes or making obstruction, there are only two options: (1) employees have to try to accept and follow the changes in working environment as it is impossible to change such things in an organization to fit a worker, or (2) employees are excluded from the organization.

The factor "Lack of patience and loss of motivation after a period of Lean implementation" is also received different opinions from experts, but this time, the proportion of consideration this as an impediment or obstruct is much higher than the above factors. Employees are who directly carry out work, but they do not have the vision as a leader. Thus, they often desire to achieve quick results and their results must be clearly visible. Then, when doing anything that does not have instant results, they easily become discouraged and lose confidence to be able to continue. At that moment, the loss of motivation and determination would lead to the stagnancy of Lean manufacturing implementation. Besides, all experts agree that in this stage, the role of leadership is extremely important. Deploying anything 
cannot always be smooth and stable since there are some periods suffering many problems and obstructing in directions as well as solutions. That leads to the stagnancy of work, which causes the boredom, faltered feelings for workers. At that time, leaders need to be present and accompany with their employees, say something to encourage, to explain to the employees about the long road that they are going and overcoming difficulties together.

The factor "Disunity at work within the group" is considered to be a hindrance to the Lean implementation. Nowadays, not only Lean but any work also needs coordination, mutual support among team members to effectively achieve the highest goal. Modern and professional working environment does highly appreciate team work instead of completely independent work. Therefore, team work skill plays an increasingly indispensable role and becomes one of the main criteria for evaluating candidates for recruitment.

\section{Barriers from the workplace}

All the experts participating in the interview agree that the factor "Culture and regulations of the country" does not cause any hindrance to the Lean implementation at the enterprises in Vietnam. They all believe that in our country there has not been any circumstance related to cultural factors or laws which cause pressure and prevent enterprises from improvement. Currently, Vietnam is now strongly focusing on the productivity improvement program as well as the quality and production efficiency improvement programs. The government currently encourages enterprises to adapt innovative programs in factory operation, build culture and continuously improve mindset for its workers and even develop preferential policies to support enterprises as much as possible. All of those are carried out in order to achieve the objective by 2020 that Vietnam basically becomes an industrial nation toward modernization. Therefore, maybe in some other countries they have rules, laws or their own industrial development policy which is noted as a barrier. On the contrary, this is not a barrier but a support and encouragement in Vietnam.

The factor "Corporate Culture" is mentioned as really hampered factor by experts. Corporate culture is a factor that needs to go through the forming process and long-term development to be built. Thus, it is not a thing that can be changed easily, and it would take a lot of time to be changed. Simultaneously, it is also seen as the skeleton of the entire organization and from that, it forms the work environment and human characteristics. All activities of the enterprise are also influenced by many elements from this platform. Therefore, while corporation culture is lack of dynamic, afraid of changing to take an interest in new things, particularly Lean, innovative thinking will not be spread in the whole system and no one has any concern or support, the deployment will be isolated and separated from the remaining operations.

"The missing and incomplete training/coaching program" includes two objects: the leadership and staff levels. For leadership, the lack of training program on knowledge and skills for their improvement received mixed opinions of the experts since the level ranged from not very hindering to really hindering. What the experts said is that leaders need to have the knowledge, skills about lean in order to set the right direction and implement work effectively. That is also the reason why experts considered the lack of knowledge and skills in training program for leaders as a hindrance to Lean implementation. On the other hand, there are experts who believed that the importance of leadership is understanding the spirit, the Lean thinking and the core problem so as to map out ideas, suitable strategies and assign the detailed or specific stages to other employees under the program. Therefore, they will consider the training and coaching 
knowledge or skills for leadership is not really necessary because without them, it does not lead to any obstruction or much hindrance. For the staff level, most experts note that lacking training program for this group as obstruction factor. The reason here is because if there is no comprehensive training program, employees will merely follow orders without knowing what they are asked to do, why to do, what are the benefits and even how to do the job.

The factor "Lack of communication and interaction between all levels and different teams" is mentioned by all experts at the degree of obstruction to a hamper. The essence of Lean requires uniform and across from top to bottom operation. In addition, to implement Lean manufacturing, it must be relevant, have coordination and support among all departments in the entire system, from office block to production block, from the planning stages until the purchase of finished products to customers. Additionally, if any problem occurs, the subordinate staff will need some information and communication with their superiors. On the two levels, with the difference of experience and working features, there will be two different perspectives. The exchange of information at this time would help to combine each other's opinions, to make evaluations, and to give comprehensive solutions to handle more.

The factor "Restrictions on space" is also received various comments from experts because they come from many sectors (working in enterprises with the varied scales and features should also have varied requirements on space, ground). Some experts consider that limited space is normal or not interfere with the design and layout because (1) small space does not mean that it is not streamlined, neat and clean, (2) being optimal or taking advantage of all the space as much as possible is also called Lean and (3) that wanting to streamline the production as well as eliminating the cost does have many solutions to carry on, not only expanding physical space. On the contrary, the experts who mention this factor as the high hindering factor believe that limited production space can cause waste in terms of transportation. This is because machines are bound in tight spaces so it is hard to arrange them optimally in order to ensure that the flow of raw materials and semi-finished products moves smoothly with the shortest distance in the chain.

The factor "Too stable working environment to form motivation" is mentioned as hampered factor to much hampered factor by most experts because one of the principles of Lean is continuous improvement. Nothing is forever stable, and stability is not always the best. For instance, even when a system has operated well, it still needs us to continue studying and improving day by day to get better and better. A leader who thinks that stable activities with no crashes or incidents is good enough and that there is no need to be improved is lack of Kaizen thinking. It means they are always self-satisfied and accept what they have already had. In fact, this is not consistent with Lean philosophy anymore because once people think so, how can they have the motivation to implement Lean strategy?

\section{Barrier from Resources}

The factor "Lack of human resource to implement Lean" is received quite different notifications from experts, identified from not really hindering to very hindering. Number of notes at normal and not unhindered factor account for higher proportion in comparison with comments at hindering factor. The experts have normal notifications since they believe that quality is more important than quantity. Some small enterprises with small scale of human resource still can perform Lean well due to their reasonable Lean assignments, great competence, positive staff attitude and high performance. Abundant amount of quantity with low quality would become meaningless and cause the Lean $8^{\text {th }}$ 
waste which is human waste. Moreover, Lean should have done with three elements: the ground, the process and the human resource. On the contrary, other experts who give notifications as hindrances believe that there are some simple ideas can be done immediately and there are some complicated ideas which need human resource for longterm development. Once missing, the work will be delayed or may not be done quickly, which leads to decreased motivation.

The factor "Lack of financial resources" is identified as an obstacle by most experts. An enterprise facing difficulties related to business situation, modest budgets is forced to allocate business support operation activities as the first priority before thinking of investing on activities to improve productivity or performance. However, there is an expert considered this factor as an unhampered factor based on the idea that the actual Lean implementation has a lot of work to do including simple things that just needs some small changes in methods, processes instead of much money investment. Besides, the enterprises with efficient activities in analysis and cost control will never accept an initial investment before having some tests to evaluate the effectiveness. Thus, they only accept new investors when they clearly see the possible benefits.

The factor "Lack of time" is divided into 2 problems: lack of time for implementing and lack of time for training. Both of them are identified as hindering factors by 5 experts. Lack of time will lead to the unenthusiastic implementation or even no implementation at all, which is certainly unsuccessful. On the other hand, there is an expert whose viewpoint of the factor "Lack of time" is normal and not hindering. Firstly, if it is lack of time for implementation or leadership, the employees themselves could absolutely manage to work overtime in some cases. In terms of science, working overtime is not encouraged and recommended. However, in a few infrequent circumstances, it is still flexibly acceptable.
Secondly, staff training does not take too much time. Knowledge that employees get actually comes from the regular sessions and daily work processes. In facts, working time accounts for the majority proportion so that the knowledge gaining from work will be more than in regular sessions. Thus, organizing training sessions takes 5 to 7 days per year is totally possible.

Experts have many differences in viewing the barrier of the element "Unqualified input equipment and materials", identifying from not very hindering to hinder; however, the hindering proportion still has to be identified. They note that the unqualified machines or materials might lead to the rate increase of defective products. When implementing Lean, it is time consuming and it is really hard to reach the standards if there are so many errors in the production line. Besides, for some specific industries which have a few specific suppliers of materials, machinery or even exclusive offers, the selection and conversion into another cooperative vendor are arduous.

\section{Barriers from Operation process}

Related to measurement problems, there are two barriers which are (1) being unable to measure benefits and the level of efficiency of Lean implementation and (2) lack of criteria, measurement system or effectiveness measurement activities. Considering factor (1), all eight experts noted that it is a high barrier. Considering factors (2), the obstruction is generally a little lower by most experts noted. However, all experts do agree that we cannot do anything well if we do not understand it or do not measure it at the beginning as we will have no idea about the following outcomes, the effectiveness as well as the gaps, the differences to come up with appropriate solutions and methods. Moreover, if we take inaccurate measurements, it will also make no sense. Nevertheless, while taking the measurements, we will have to face some problems. In fact, there are some innovative activities such as improvements related to occupational safety which needs 
acute senses to understand, to feel that it will bring positive results since it is too difficult to be measured. Sometimes, there are some improvement projects such as instant conversion projects that have just done the first time since the appearance of Lean implementation so that there are no previous figures to make any comparison between the past and the present days.

"Strategy changes and no close link with the strategy" includes two small notions: (1) Unclear - Unstable Lean implementation strategy and (2) Lean implementation activities which do not meet the strategy and overall objectives of the business. Both of them are mentioned as a hindrance by most experts. Unclear strategy may make people confused about how to do. Strategy changing constantly from one thing to another all the time takes people a lot of time to start again from scratch every time there is a small change. Besides, when doing whatever it is, people always need to have a period of time to detect mistakes and then find ways to deal with and improve as well. Therefore, if the strategy keeps changing persistently, there will be lack of time to check the pros and cons of activities. Furthermore, the objectives and general strategies of the business are the basis and the orientation to continue all subsequent activities. Thus, though the implementation of Lean is to create value for the enterprise, to help businesses become better, it would become meaningless once the deployment does not stick or support the unified strategy. As a matter of fact, an activity which does not serve the strategy and goes with its orientation will not be supported or cooperated.

The element "Maintain unstably and fall into old paths" is considered to hinder the implementation of Lean. This factor is almost similar to the constantly changing strategy. The lack of stability raises negative human feelings like being doubtful, unconfident, undetermined and unenthusiastic. As a consequence, the only way is to keep going on the old and unsuitable paths, which means that there will be a lot of errors and limitations.

The factor "Failure in previous Lean projects" is mentioned only at normal factor, hindering but not significantly. There is even a notification that this is not a barrier element at all. All failures have the same general explanation why the project failed in the previous Lean. Anyway, it does not mean that there is no chance to do it again or the upcoming deployment will continue to fail. It is totally irrational and baseless. The crucial thing is from that failure, are the enterprises able to perceive their problems (What was wrong? Was the process unsuitable? And so on) and solve the problems. Thus, sometimes those mistakes are really helpful as they provide more practical experience for enterprises so that next time will be done better.

Barriers from the integration with customers

Factor "Lack of customer focus" has different perspectives perceived from the experts. The difference is because most experts believe that a great performance of Lean should be applied throughout the entire supply chain, where customers are one of the key chains. Finally, the implementation of Lean is to improve production, to meet more rigorous demands of more clients so that the sales will increase and the satisfaction level of customers will be enhanced. Then, we can see that all of them are closely linked to each other and the improvement goals are also for customers, who can contribute to the company's revenue. Moreover, companies' lack of focus on customers sometimes leads to their exceeded and unnecessary activities fulfilling requirements. This will be the better for output products and customers but at the angle of Lean, enterprises are generating more waste by implementing things that customers do not require and do not feel essential. In contrast, from the view of the other expert who considered this factor is not impeded, Lean is the work done internally in the 
factories, eliminating the waste generated in the production process and not related or affected to customers.

Factor "Lack of cooperation and support from customers" also receives two different streams of opinion. Most of the experts mentioned that this factor do not interfere or negligible due to two reasons: (1) For businesses operating in the retail sector or B2C FMCG manner, the number of customer is very large and they buy or build a direct relationship with the channel distributors, dealers, supermarkets instead of the manufacturers. Therefore, they cannot cooperate, support for the enterprises and they do not have any duty to do it. (2) For those enterprises operating under the model of $\mathrm{B} 2 \mathrm{~B}$, the number of clients and customers will be fewer but they often establish a deeper relationship with the manufacturers. Some customers also sent their teams to factories so as to cooperate with the factory improving the production lines. Nevertheless, it does not mean that only when there are customers or clients, do the enterprises perform Lean. In fact, the enterprises have to make a plan to actively implement Lean themselves. On the other hand, the remaining experts mention the factor at hindering level to very hindering level. The reason is that if customer do not cooperate, support enterprises, it is impossible to know what their needs is and how to meet their expected demands, how to minimize the negative impacts on customers. When they do not know clearly, employees must try their best to complete as much as possibly for customers, which is likely to have the consequence of excess and waste for those companies.

Factor "Heterogeneity in customer requirements" or customers want products to be personalized based on their own requirements also gets two different streams of opinions when most of the experts said it was a hindrance. The others noted it was a normal factor or did not give any comment. The first stream is that each client has specific requirements and none of which are identical. Then, the implementation will certainly be complex and more difficult because it is impossible to have a general method or standard for every requirement of different customers. On the other hand, the second stream is that this element inclines to improving the quality of service rather than improving the processes. This is normal factor because it is, in fact, what customers want nowadays and what any company faces regularly. Thus, the mission of the enterprises is to deal with this problem if they want to maintain their competitive advantages in the market. In conclusion, it is considered as a default that every enterprise must strive to achieve and absolutely not an obstacle to them.

\section{Barriers from the integration with suppliers}

Both factors "Lack of communication and the impact on suppliers" and "Lack of cooperation and support from the vendor" are mentioned as an obstacle. In particular, the notifications of two factors given by 6 different experts are the same. In reality, when the delivery is delayed or the products are not the right requests of the company, the company will not able to manufacturing anything until the appropriate materials arrived. This is such a problem of wasting time for waiting, which will cause some bad outcomes for Lean implementation. Besides, the problem can possibly occur if there is lack of information from enterprises to suppliers and support from suppliers to enterprises.

The final element in the group of factors about suppliers and also the last element in the barrier elements accentuated in this study is "Unguaranteed supply chain and logistics system". Just like the last element in the group of factors about customers, this factor is given two different streams of opinions when most experts said it is a hindrance, the others considered normal or thought it was not an obstacle and the other case did not leave any comment. The first idea is that if enterprises 
comply and do everything in their factories very well towards Lean, there are some factors from supply chain management of outer effects which enterprises are unable to deal with, the quality of the whole system will not be guaranteed. As for the other idea, experts explained that the unguaranteed quality of supply chain management and logistics system is due to either the suppliers or the businesses themselves. If the cause comes from the businesses, it can be considered whether the application of Lean should be used to improve or not. If it basically comes from the suppliers as perhaps they are unable to meet the requirements, the suppliers themselves or the enterprises have to use their influences to require for overcoming the problems. At this time, Lean can neither affect nor change the situation. In another case, an expert defined that Lean actions are just encapsulated within internal factories which is more specific in the production chain. Therefore, Lean concentrates more on production parts, which is not or just slightly related to procurement and support parts, which means that the influence rate of this factor is not considerable.

\subsection{Discussion}

Factors about "Leadership" are considered important and most influential to Lean implementation. The leaders are the most powerful people who make or approve almost all the final decisions for the business. Indeed, every activity from leaders affects all the stages and all their subordinates. Therefore, only when the leaders themselves realized the benefits and efficiency of Lean, they have the commitment, deep concern, support and enthusiasm to give priority to the implementation activities. At the same time, the spirit of implementing drastically, seriously is also one of the most crucial factors spreading the Lean philosophy deeply in humans' minds. Consequently, every thought and deed of them has a significant impact on development paths and destiny of the companies, thereby affecting the activity down below. In addition, all the elements in the other remaining groups are affected by this group.

"Workers" are people who directly carry out the work, create the final results so that the barriers from this group factors also affect the Lean implementation of enterprises. Nevertheless, since there are still management and supervision activities from the superiors and there is the ability to replace employees simply as well as quickly, these barriers can be controlled and limited. Compared with the leadership factor, this factor stays in the lower obstruction.

The "Culture and national regulations" factor which causes pressure on businesses and prevents them from operating effectively may happen in other countries, but at least not in Vietnam. Culture, strategy and business objectives are key elements forming the working environment, personalities and unique features for enterprises. They are also the platform to deploy all activities and work. Therefore, if the Lean implementation is not appropriate, not supportive of the goals, the strategy or it is just built unreasonably, the Lean implementation will become pointless and valueless. Besides, Lean enhances the cooperation in team work, the regular exchange of information and continuity among different levels or departments. Lean implementation group should be developed in the form of multi-functional group. Lack of these elements is an obstacle to implement the Lean strategy. Further, the training activities in order to provide knowledge and skills about Lean for workers besides the organized classroom, there are many things to learn in real working environment. This form of training should account for the majority proportion because most of the workers are working fulltime and the contents should be much more practical. Then, employees can have chance to apply theories into reality and remember information more permanently.

"None of measurement activities, lack of measurement activities or too many errors in 
measurement" results in many bad outcomes such as being unable to evaluate the effectiveness of implementation, lack of convincing power and lack of idea as to what and how to improve the strategy. "Failure in the Lean project in the past" does not mean that it will continue to result in the failure of the current project. The crucial things now are through and experience learnt from previous mistakes. From that experience, the business will better operate and will not go on the old path.

Assessment of Lean has to be made on the entire supply chain management because every chain in the systems always links to each other which means that the latter depends on the former. Besides, businesses must have a closed 2-way link between customers and suppliers to ensure end-to-end chains are streamlined and efficient.

Consequently, there are several factors which have not been unified in all experts' views. They need to be clarified by an extensive study later.

\section{Conclusions}

Overall, this study explores seven key barriers inhibiting Lean implementation on the basis of in-depth interview with eight experts experiencing Lean implementation in eight manufacturing companies: barriers from leadership; employees; workplace; resources; operation process; the integration with customers; and the integration with suppliers. Especially, the barrier factors about leadership are considered important and most influential to Lean implementation; and the barriers from aspects such as: workers, culture and national regulations, none of measurement activities, lack of measurement activities or too many errors in measurement and failure in the Lean project in the past also hinder the Lean implementation of enterprises.

Consequently, this study provides implication for various agents.

Firstly, in terms of leadership, to be able to achieve the effectiveness of Lean implementation, shaping perceptions and leadership thoughts is far more essential than developing knowledge and skills. Therefore, enterprises should appoint leaders participating in the conference program, workshops on improving quality, improving production efficiency to gain more information and knowledge from experts as well as the head of other enterprises. Then, there will be more opportunities to develop relationships and to compare your business position to others even from the same fields or different fields. In addition, businesses also need to send leaders to training courses at least 1-2 courses per year. However, training here is not about knowledge or professional skills, it is all about raising awareness, visions and strategic planning skills to build up and disseminate the Lean culture for enterprises. For multinational company, a good way is sending leaders from Vietnam to factories in other countries as well as the parent company for training purposes.

Secondly, for subordinates, shaping Lean thinking to their subconscious part, making it like their habits which they have normally do on their daily life is vital. Therefore, enterprises on manufacturing sector do not require technology as high as enterprises on fashion and textile or plastic industry. Those enterprises have to particularly care about the issue because of the needs of lots of unskilled workers, which means that it is really hard to manage and disseminate the knowledge and awareness to them. Besides, workers also need more training courses focusing on professional skills, practical skills about Lean since they are directly involved in production and machinery operation activities. In addition, there should be a possibility to empower employees, depending on the functions and levels, in order to give the employees feelings of that they are taken seriously, their contributions are trusted and recorded. Moreover, that is also a good way to decrease the amount of work for leaders, to give them more time focusing on more important things, solutions and that would 
help eliminating time consumption. Besides, the leader should have spent time observing those potential people in a particularistic way. Additionally, at the beginning of Lean implementation, enterprises need to develop a system to encourage and reward dedicated employees in the new implementation, which would be a useful method to boost their morale, give them more motivations and shape their minds positively, quickly and easily as well.

Thirdly, for suppliers, strengthening the links between businesses and suppliers through various activities to build, develop and maintain long-term partnerships with each other, especially the major suppliers or strategic suppliers who are hard to replace. Typical activities could be tours for leaders from both company to visit each other; to regularly assess the performance from suppliers in terms of quality and actively propose solutions for problems so as to raise the output quality as well as productivity; to ask for permission of suppliers about sending a technical team from the company to support directly and work with suppliers; to allow suppliers to install machinery and production lines right in the company if enterprise has surplus area which has no plan to use.

Finally, for customers, the regular twoway exchange of information or building relationships is as important as those with suppliers, especially major customers which account for a significant proportion of total sales.

With the above results, this study calls for quantitative research to verify the results as well as make more concrete contributions to the field of Lean research and Lean implementation

\section{Acknowledgment:}

This research is funded by Ho Chi Minh City University of Technology - VNU-HCM, under grant number: TQLCN-2016-93; which is very appreciated. Also, we would like to express our sincere thanks to the experts of manufacturing companies who involved the in-depth interviews.

\section{References}

Akbulut-Bailey, A.Y., Motwani, J., \& Smedley, E.M. (2012). When Lean and Six Sigma converge: a case study of a successful implementation of Lean Six Sigma at an aerospace company. International Journal of Technology Management, 57(1/2/3), 18-32.

Albliwi, S., Antony, J., Lim, S.A.H., \& van der Wiele, T. (2014). Critical failure factors of Lean Six Sigma: a systematic literature review. International Journal of Quality \& Reliability Management, 31(9), 1012-1030.

Albliwi, S.A., Antony, J., \& Lim, S.A.H. (2015). A systematic review of Lean Six Sigma for the manufacturing industry. Business Process Management Journal, 21(3), 665-691.

Alinaitwe, H.M. (2009). Prioritising Lean Construction Barriers in Uganda's Construction Industry. Journal of Construction in Developing Countries, 14(1), 15-30.

Alukal, G. (2003). Create a Lean, Mean Machine. Quality Progress, 36(4), 29-35.

Angelis, J., Conti, R., Cooper, C., \& Gill, C. (2011). Building a high-commitment lean culture. Journal of Manufacturing Technology Management, 22(5), 569-586.

Ballard, G., \& Tommelein, I. (2012). Lean management methods for complex projects. Engineering Project Organization Journal, 2(1-2), 85-96.

Berggren, C. (1993). Lean Production-the End of History? Work, Employee and Society, 7(2), 163-188

Bhasin, S. (2012). Prominent obstacles to Lean. International Journal of Productivity and Performance Management, 61(4), 403-425.

Bhasin, S., \& Burcher, P. (2006). Lean viewed as a philosophy. Journal of Manufacturing Technology Management, 17(1), 56-72. 
Boyle, T.A., Scherrer-Rathje, M., \& Stuart, I. (2011). Learning to be lean: the influence of external information sources in lean improvements. Journal of Manufacturing Technology Management, 22(5), 587-603.

Creswell, J. W. (2013). Research design: qualitative, quantitative and mix methods approaches. London: Sage Publication

Crute, V., Ward, Y., Brown, S., \& Graves, A. (2003). Implementing Lean in aerospace - challenging the assumptions and understanding the challenges. Technovation, 23(12), 917-928.

De Souza, L.B., \& Pidd, M. (2011). Exploring the barriers to lean health care implementation. Public Money \& Management, 31(1), 59-66.

Dubrin, A. (2011). Essentials of Management. $9^{\text {th }}$ Edition. Mason, OH: South-Western, Cengage Learning.

Eswaramoorthi, M., Kathiresan, G. R., Prasad, P. S. S., \& Mohanram, P. V. (2011). A survey on lean practices in Indian machine tool industries. The International Journal of Advanced Manufacturing Technology, 52(9-12), 1091-1101.

Hirayama Việt Nam. (2015). Thành công từ việc áp dụng Hệ thống sản xuất tinh gọn. Available: http://hirayamavietnam.com.vn/thanh-cong-tu-viec-ap-dung-thong-san-xuat-tinh-gon/. [truy cập ngày 03/03/2016].

IMQ Corporation. (2014). Cơ hội ngành may mặc và khả năng doanh nghiệp Việt Nam?. Available: http://www.tuvanquanly.vn/index.php/dao-tao-hoi-thao/198-chuong-trinh-dao-tao-lean-khoa-14-giam-chi-phinguyen-vat-lieu-va-quan-ly-tinh-gon-hon-lean-production-mfca. [truy cập ngày 03/03/2016].

Jadhav, J.R., Mantha, S.S., \& Rane, S.B. (2014). Exploring barriers in lean implementation. International Journal of Lean Six Sigma, 5(2), 122-148.

Lixia, C., \& Bo, M. (2010). Research on the five-stage method for Chinese enterprises to implement lean production. Proceedings of 2010 International Conference on Logistics Systems and Intelligent Management, 1135-1138.

Lê, T. (2013). Áp dụng quản lí sản xuất tinh gọn trong doanh nghiệp. Available: http://www.baohaiquan.vn/Pages/Ap-dung-quan-li-san-xuat-tinh-gon-trong-doanh-nghiep.aspx. [10/04/2013].

Marodin, G.A., \& Saurin, T.A. (2015). Classification and relationships between risks that affect lean production implementation: A study in Southern Brazil. Journal of Manufacturing Technology Management, 26(1), 57-79.

Melton, T. (2005). The benefits of Lean Manufacturing: What Lean Thinking has to offer the process industries. Chemical Engineering Research and Design, 83(6), 662-673.

Murman, E., Allen, T., Bozdogan, K., Cutcher-Gershenfeld, J., McManus, H., Nightingale, D., Rebentisch, E., Shields, T., Stahl, F., Walton, M., Warmkessel, J., Weiss, S., \& Widnall, S. (2002). Lean Enterprise Value Insights from MIT's Lean Aerospace Initiative. $1^{\text {st }}$ Ed. New York, NY: Palgrave.

Nguyen, D. M., Nguyen, D.N., Lê, A.T. (2015). Framework of Critical Success Factors for Lean Implementation in Vietnam Manufacturing Enterprises. VNU Journal of Science: Economics and Business, 31(5E), 33-41.

Nguyen, T., D., N. \& Bui, N., H. (2010). Applying Lean Manufacturing in Vietnam through some cases, Journal of Development \& Integration, 8, $41-48$.

Nordin, N., Deros, B.M., \& Wahab, D.A. (2010). A Survey on Lean Manufacturing Implementation in Malaysian Automotive Industry. International Journal of Innovation, Management and Technology, 1(4), 374-380.

Panizzolo, R., Garengo, P., Sharma, M. K., \& Gore, A. (2012). Lean manufacturing in developing countries: evidence from Indian SMEs. Production Planning \& Control, 23(10-11), 769-788.

Pedersen, E.R.G., \& Huniche, M. (2011). Determinants of lean success and failure in the Danish public sector: a negotiated order perspective. International Journal of Public Sector Management, 24(5), 403-420.

Peters, A. (2010). Your Journey to Lean: Continuous Improvement Supported by Tools. Available: http://www.wipro.com. [truy cập ngày 02/03/2016].

Pirraglia, A., Saloni, D., \& van Dyk, H. (2009). Status of lean manufacturing implementation on secondary wood industries including residential, cabinet, millwork, and panel markets. BioResources, 4(4), 1341-1358. 
Pradabwong, J., Sriariyawat, N., \& Temiyasathit, C. (2012). An Investigation of Lean Implementation Status in Thai Manufacturing. Applied Mechanics and Materials, 110, 4050-4056.

Ringen, G., \& Holtskog, H. (2013). How enablers for lean product development motivate engineers. International Journal of Computer Integrated Manufacturing, 26(12), 1117-1127.

Sahwan, M.A., Rahman, M.N.A., \& Deros, B.M. (2012). Barriers to Implement Lean Manufacturing in Malaysian Automotive Industry. Jurnal Teknologi, 59(2), 107-110.

Shah, R., \& Ward, P.T. (2003). Lean manufacturing: context, practice bundles, and performance. Journal of operations management, 21(2), 129-149.

Shah, R., \& Ward, P.T. (2007). Defining and developing measures of lean production. Journal of operations management, 25(4), 785-805.

Swamidass, P.M., Baines, T., \& Darlow, N. (2001). The role of manufacturing and marketing managers in strategy development: Lessons from three companies. International Journal of Operations \& Production Management, 21(7), 933-948.

Taleghani, M. (2010). Key factors for implementing the Lean manufacturing system. Journal of American science, 6(7), 287-291.

Taner, M.T., Sezen, B., \& Antony, J. (2007). An overview of six sigma applications in healthcare industry. International Journal of health care quality assurance, 20(4), 329-340.

Tracey, M., Vonderembse, M.A., \& Lim, J.S. (1999). Manufacturing technology and strategy formulation: keys to enhancing competitiveness and improving performance. Journal of Operations Management, 17(4), 411-428.

Tổng cục Tiêu chuẩn Đo lường Chất lượng (Directorate for Standards, Metrology and Quality). (2015). Tăng năng suất lao động 30\% nhờ áp dụng Mô hình Quản lý tinh gọn (LEAN) - Chia sẻ kinh nghiệm của Công ty TNHH may Hưng Nhân - Tổng Công ty Đức Giang. Available: http://www.tcvn.gov.vn/sites/head/vi/tin-chi-tiet-nscltang-nang-suat-lao-dong-30-nho-ap-dung-mo-hinh-quan-ly-tinh-gon-lean-chia-se-kinh-a2ea0b46.aspx. [truy cập ngày 19/04/2016].

Womack, J. P., \& Jones, D. T. (2010). Lean thinking: banish waste and create wealth in your corporation. NY: Simon and Schuster.

Womack, J. P., Jones, D. T., \& Roos, D. (2007). The machine that changed the world: The story of lean productionToyota's secret weapon in the global car wars that is now revolutionizing world industry. NY: Simon and Schuster.

Womack, J.P., \& Jones, D.T. (1996). Lean Thinking: Banish Waste and Create Wealth in Your Corporation. New York, NY: Simon \& Schuster, Inc. 